\title{
How is Economic Growth Correlated to Index Growth?
}

\author{
Aryan Chordia ${ }^{1}$ and Karan Gurbani\#
}

${ }^{1}$ Neeraja Modi School, India

\#Advisor

\section{$\underline{\text { ABSTRACT }}$}

This study will mainly focus on the relation between GDP growth and stock market index growth through various methods like the Pearson product-moment coefficient correlation, comparing the theoretical world to the real-world situation, and finally by looking at consumer sentiments and confidence. This could help various analysts, economists, and even the general public. During the study, various trends have been found and sometimes there were contradicting results. But finally the Pearson product-moment coefficient correlation proved that there is no correlation between GDP growth and stock market index growth, but then both of them drive from consumer confidence and consumers' future actions.

\section{Literature Review}

The correlation between economic growth and index growth is a recurring question amongst analysts and investors. According to the International Monetary Fund (IMF), gross domestic product (GDP) could be viewed in 3 different ways which include the spending approach also known as the expenditure approach. This adds up the value of purchases made by final users, for example, the consumption of food, televisions, and various other expenses done by households, the investments in machinery by companies, and the purchases of goods and services by the government and foreign institutions. Stock market growth heavily relies on demand and supply of stocks which is influenced majorly by firm's surplus, which is further affected by consumption of goods and services and the net exports these to affect the GDP, as it is calculated by adding consumption, public spending or government spending, investments by multinational companies (MNCs) or other countries government and net exports. Therefore, in a theoretical environment, the increase in stock price should exactly match real GDP growth. The underlying economy of a country translates into a company's profits, thus into Earnings per Share (EPS), which eventually determines the price of a company's stock.

To obtain a forward-looking estimate on the topic, typical research and models have been proposed on the correlation between GDP growth and Index growth for example the MSCI Inc. (2010) shows a positive possible link between economic growth and stock market returns both theoretically and practically). According to Prof. Jeremy Siegel (1984), the reason for rates of Index growth not to follow GDP growth is because of globalization and the fact that multinational corporations play an increasingly important role in the economies. Accompany this Jay Ritter (2005), negative correlation also exists because stock returns are determined by improving values of the selected measures of corporations' performance like P/E and ROE which reflect both (i) earnings and (ii) the amount of capital contributed by investors, and not by the profits corporations generate in the economy. Research by Sachin Trivedi from UTI mutual fund (2019), suggests that there seems to be no clear connection between economic growth and market returns.

On the contrary, Monika Halan from Livemint (2011) reports that there is a rough estimate between the rate of growth of GDP and market return. A model proposed by Wise-owl (2016) shows there is a correlation in the theoretical environment but not in the practical world. 
In a review of previous studies, we found that some models have correlated economic growth and index growth from various perspectives. These studies included one fascinating approach:(i)by looking at the theoretical environment which most of the researches have done, wise owl (2016) for example they compared the theoretical environment versus real economy and then discussed potential reasons for disproportionate results. The other writers report that there is no correlation between the topic at hand; therefore, we will study various theories starting with comparing the real economy with the theoretical environment;(ii) we will see how does economy affects consumer spending thereafter affecting stock market growth; finally, we will use the Pearson correlation coefficient as a comparing method between economic growth and index growth.

\section{Theoretical Environment V/S Real Economy}

In this case, we would only consider real GDP and not nominal GDP: As discussed earlier Gross domestic product or GDP growth and stock market index growth closely links together as GDP is calculated with the addition of consumption, government spending, investment, and net exports and how stock market relies on the market forces of demand and supply where demand is majorly controlled on the willingness and ability of an investor for a particular stock or equity in a firm which is influenced by the operating profits of a firm thereafter affected by consumptions and the number of exports done by the firm which affect the GDP growth. Investment refers to the bonds issued and sold to private banks, investors, or firms indirectly refers to borrowing from foreign governments, financial institutions, and also local investors which is the country's population. Many financial institutions that are listed on the stock exchange work in these T-bills or government bonds, as they are the most secure investment with a fixed rate of return that makes up a small chunk of profit for various firms like Life Insurance Corporation of India, Morgan Stanley, etc. The government even launch IPO or initial public offering like the Indian government did to increase liquidity and increase the money in hand to boost the economy adding to this they even privatize various government assets as Indian Railway Catering and Tourism Corporation (IRCTC) has been planned.

This approach is intended to provide shares of private companies in the stock market. This money is used to increase government spending and also to show a certain amount in a country's investment that links to how GDP is calculated.

Even after a connection to the academic environment, nothing works in the same real situation during the 2008 financial crisis the Dow Jones Industrial Average sold below 10,000, and overall, the stock market fell by about $40.54 \%$ but GDP fell by about $0.3 \%$ even though for 2009 The market increased by $43.89 \%$ but GDP decreased by $2.8 \%$ in the USA. In the case of Canada in 2008 the stock market fell by $35.03 \%$ and GDP increased by $1.0 \%$ but in 2009 the market index shares grew by $30.69 \%$ but GDP fell by $2.9 \%$. However, some of the reasons for these bizarre results could be:

1. Valuations are Volatile: The market determines the value of a company and various components may influence these valuations, e.g., sentiment, confidence, emotions

2. Expectations: Expected economic growth may already be built into the prices and thus reduces future realized returns

3. Dilution: New share issuances dilute return on equity for existing investors, therefore capital growth may be lower than growth in corporate earnings

4. Dividends: Stock market valuations may be impacted by a company's willingness to pay dividends. Not paying a dividend could result in a stock trading at a discount to its 'net value' and vice versa

5. Globalization: It makes sense to look at the world every day but not the local markets. A company can produce parts of its business outside the country of origin and export a portion of its profits through offshore sales. Parts of the company's international production process are not reflected in the country's GDP. 
6. Impact of Central Bank Policies: In recent times, the role of Central Banks and their economic policies have had a significant impact on stock market recovery. The latest example of this is the Federal Reserve Bank's (FED) 'Easy Cut' policy.

7. Private Sector Release: Stock markets track only the performance of listed companies. Although these companies are generally the largest in the country and have a strong financial burden, private companies or sectors that contribute to the country's GDP are not included in this revenue.

8. M\&A Activity: Consolidation and acquisitions often lead to significant returns for shareholders and the impact on the real economy is of very little importance.

9. Political and Media Influence: Both politics and the media have a significant impact on stock market ratings and market perceptions. Especially in countries where the media is under government control and the news may not be 'really authentic', we often see more differences than markets that have less impact on the government.

\section{Effects of Stock Market on GDP Growth}

The securities market is commonly an indicator of sentiment and it affects GDP. GDP measures the output of all goods and services within the economy. Because the stock exchange rises and falls, so do sentiments in the economy. When sentiments change, government spending will eventually accelerate GDP growth. However, stock markets can have both negative and positive effects on GDP.

GDP runs mainly through spending and investment. It's expressed as a percentage then the expansion rate is compared from one period to a different. Some components that compose GDP are:

1. Consumer spending, which is that the primary driver of most GDP

2. Business costs like buying new plants and equipment, hiring workers, investing in new technologies, and building new offices and factories.

3. Exports, which are sold internationally from domestic companies to consumers.

4. Government expenditure including subsidies for roads, bridges, and industries within agriculture.

All of the above components that frame GDP are influenced by investors: - either negatively or positively through the stock market.

\section{How does the Bull Market affect GDP growth?}

It is the time when the Stock market value is rising or the prices are going up and everything is going fine. During this time the stock market index growth is affecting GDP growth or gross domestic product primarily by including financial conditions and consumer confidence.

In this time, firms issue new shares of equity to raise money which then can be used to invest in new projects, $\mathrm{R} \& \mathrm{D}$, make bulk deals, or to allot to the HR department for hiring more labor or to expand its operation in the international market to earn more revenue. These steps taken by a firm could help the GDP grow as this will increase exports or increase business spending.

While stock prices are rising, investors and consumers will have more wealth which increases optimism in the economy about their future. They might borrow more and save less. This would increase their cash in hand thereafter affecting their spending which again adds up to GDP growth.

However, during this time there isn't an increase in government spending as the economy is booming and doesn't need any extra support from the government. 


\section{How does the Bear market affect GDP growth?}

There is a risk of a stock market crash or recession when the stock market depreciates or the stock price falls during this time, which often includes two consecutive quarters of negative- or contract-GDP growth. This hurts the sentiments of consumers and investors.

In a recession market, investors go out of their way to sell stock to avoid losses on their investments. Typically, those losses lead to fluctuations in consumer spending, especially if there is a fear of a recession.

Once consumers have reduced their costs and debts, they are saving, reducing consumption, and thereby hurting the sales and revenue of companies in the economy. To deal with this, companies will cut costs and cut jobs for survival in the economy, eliminating growing employment and certainty in the economy. In this case, consumption and business spending will decrease, which will reduce GDP growth.

All of those factors lead to a loss of consumer and business confidence, resulting in less investment in the stock exchange. Reduction in spending and investment due to low confidence will ultimately hurt GDP.

Therefore, when GDP grows, corporate revenue increases, which reverses the change in stock price when GDP falls, resulting in lower costs for businesses and consumers, which drives markets lower. However, whether it is the bull market or the bear market, the exchange will have some effect - indirectly on GDP and therefore the economy as a whole.

Moreover, during this time the government spending even increases as the economy needs external pressure to shift the aggregate demand curve towards rightwards and get closer to the optimum point.

\section{Pearson Product Moment correlation coefficient as a comparing method}

We would consider the data of two developed countries, Canada and the USA, and three developing countries, India, China, and South Africa. The reason to choose for 5 different country and stock market indices integration is to get a better and wider perspective on the subject and eliminate bias as well as a lookup for the range of years within 200019, Regarding economic growth of a country to not confuse the data we will only look upon GDP and not GNP or other tools and stock market index growth.

We will be calculating the correlation of how directly or inversely the economic growth of a country affects the stock market index growth for which we plan to use the Pearson Correlation coefficient.

India

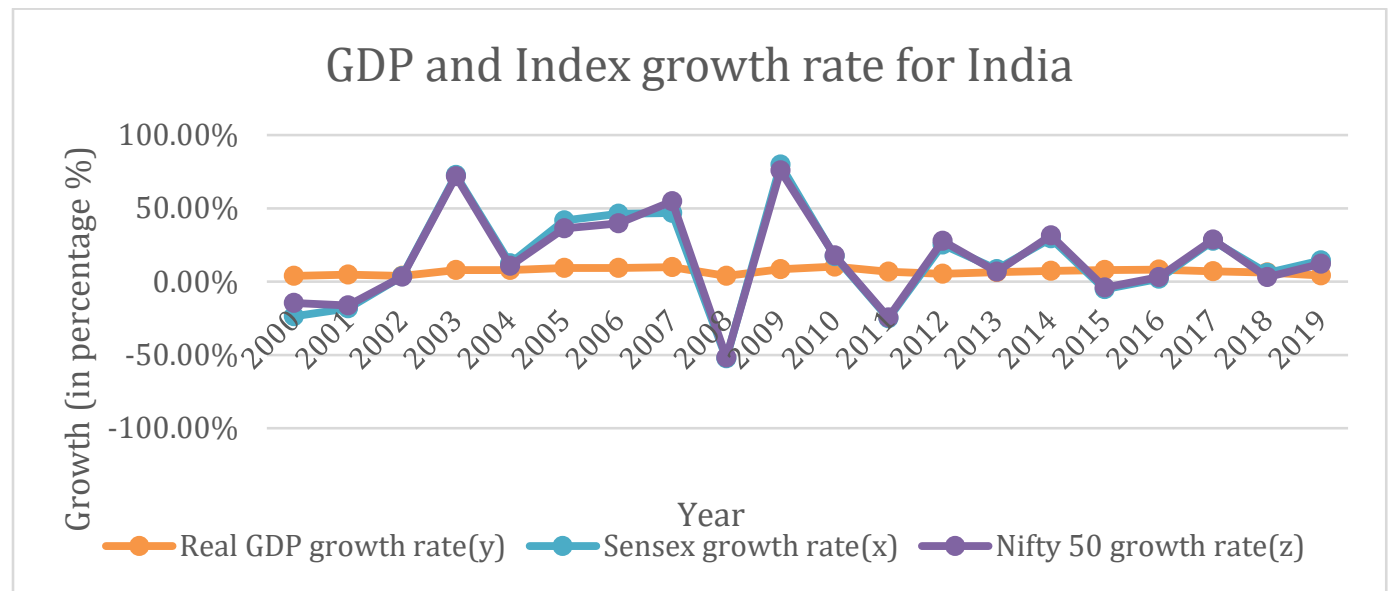

Figure 1: Shows a line graph for real GDP, Sensex growth rate and Nifty 50 growth rate 
India, an emerging market for investments, has the Pearson's $r$ (Pearson's Correlation Coefficient) of 0.623 for Sensex and GDP growth rate and for Nifty 50 the values come out to be 0.616 , which depicts a strong positive correlation between the Sensex growth rate and Economic growth rate of India. This result helps to strengthen the connection between the two $\mathrm{X}$ and $\mathrm{Y}$ variables which are real GDP growth rate and Sensex growth rate.

\section{United States of America (USA)}

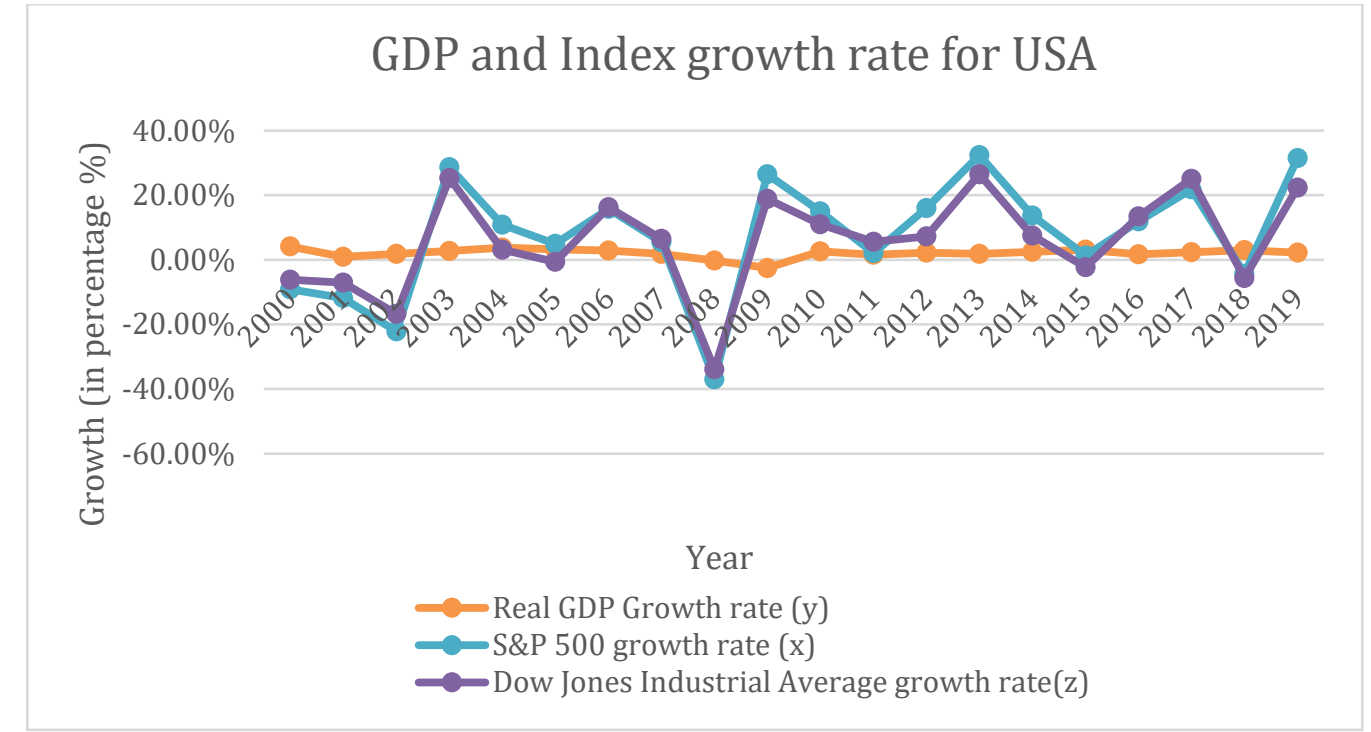

Figure 2. Shows a line graph for real GDP, S\&P 500 growth rate and Dow Jones Industrial Average growth rate

The USA, a developed nation, has a value of 0.052 (rounded off to 3 significant figures) for the relation between S\&P 500 growth rate and real GDP growth rate and Dow Jones Industrial Average growth rate compared to real GDP growth rate the correlation coefficient comes out to be 0.046 although the value comes out to be a positive integer, which shows a positive correlation between real GDP growth rate and S\&P 500 and Dow Jones Industrial Average growth rate, however, the value is so small it becomes insignificant. This helps us to understand the relation of the $\mathrm{X}$ and $\mathrm{Y}$ variable in a developed economy.

\section{China}

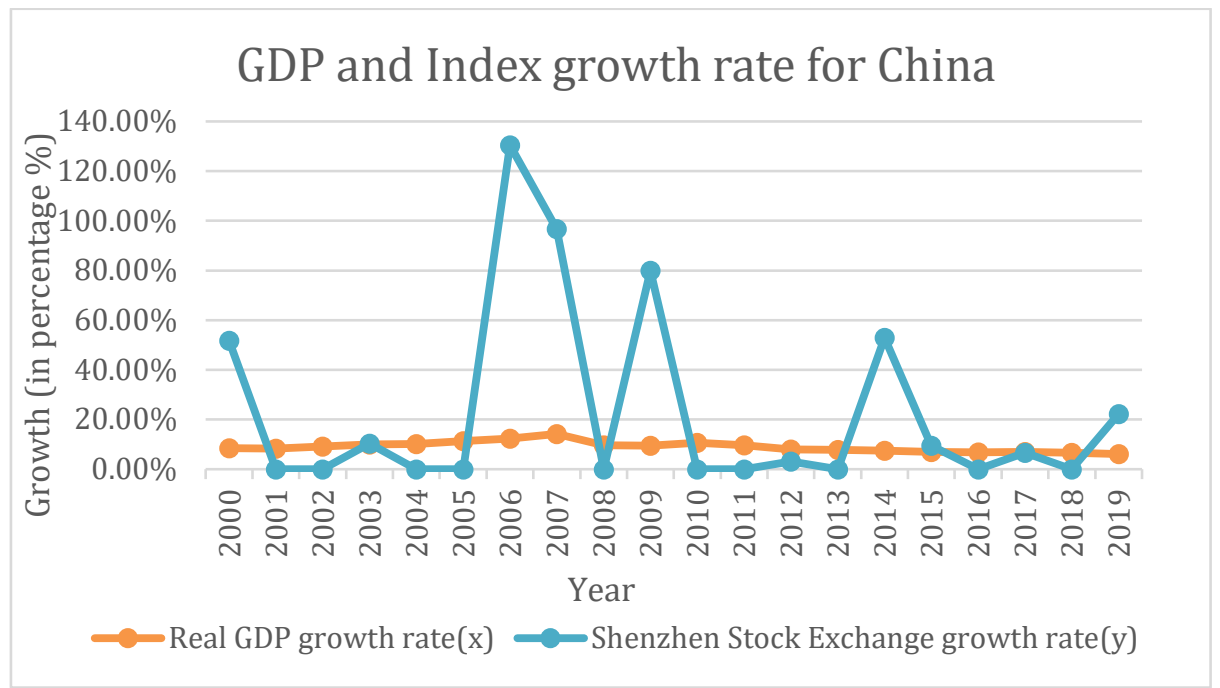

Figure 3: Shows a line graph for real GDP and Shenzhen Stock Exchange growth rate 
China, another developing country, has a Pearson's $r$ of 0.509 , which depicts a strong/ medium positive correlation between the Shenzhen Stock Exchange growth rate and China's real GDP growth rate.

\section{Canada}

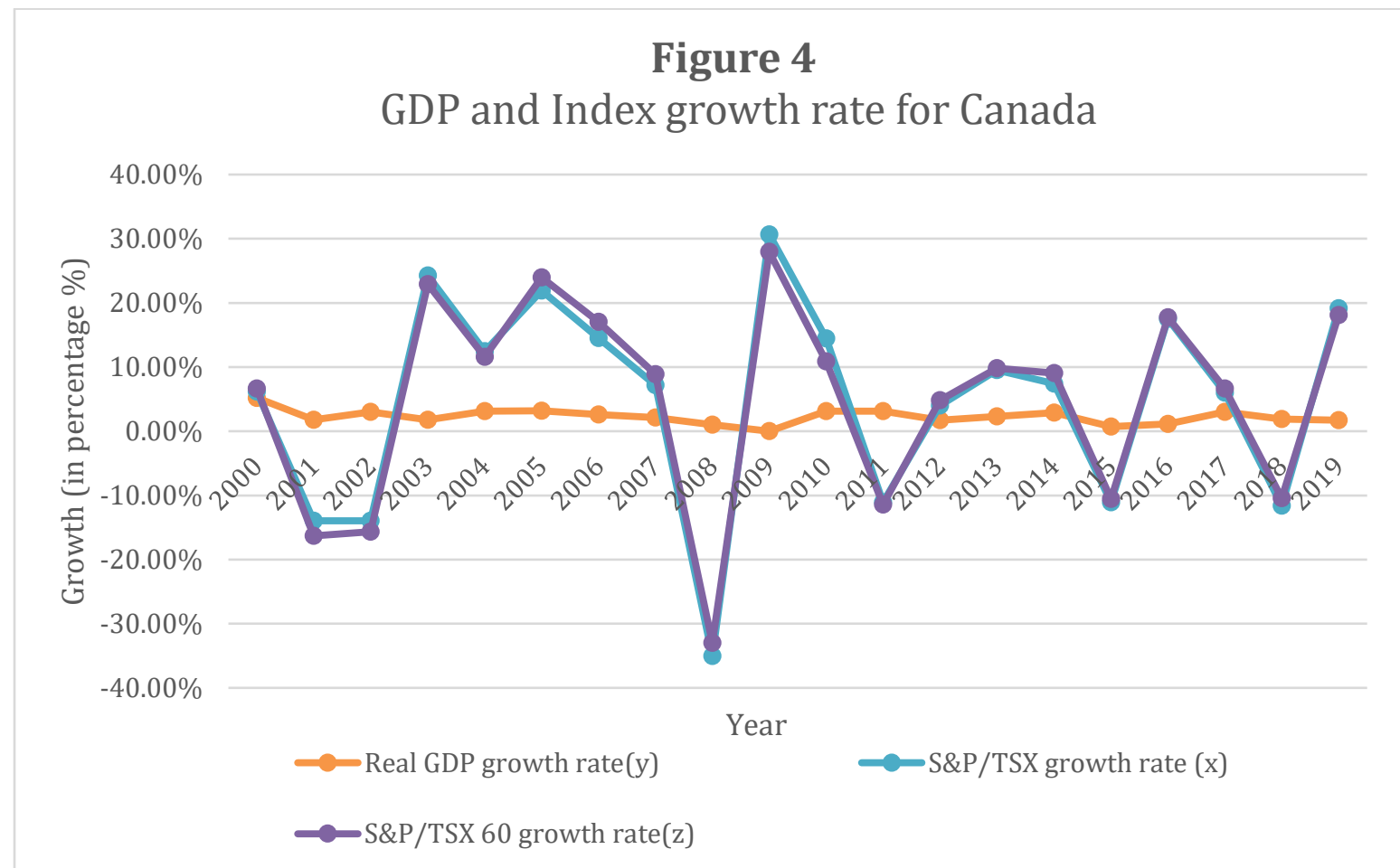

Figure 4: Shows a line graph for real GDP, S\&P/TSX growth rate and S\&P/TSX 60 growth rate

Canada, a developed nation, has a value of 0.036 for S\&P/TSX and a value of 0.484 for S\&P/TSX 60 although the value comes out to be a positive integer, which shows a positive correlation between real GDP growth rate and $\mathrm{S} \& \mathrm{P} / \mathrm{TSX}$ and S\&P/TSX 60 growth rate, however, the value is so small it becomes insignificant.

\section{South Africa}

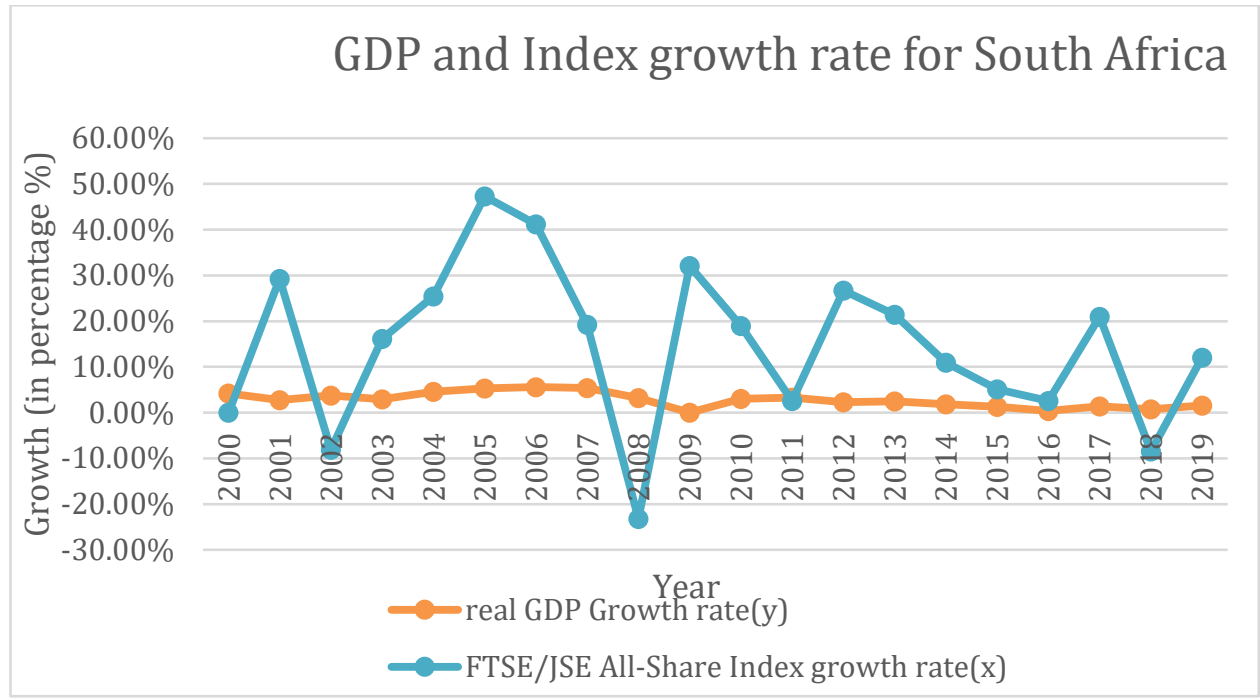

Figure 5: Shows a line graph for real GDP and FTSE/JSE All- Share Index growth rate 
South Africa, a developing country, has a value of 0.284 for Pearson's $r$, which shows a positive correlation but is not as strong as seen in the case of India or China.

These tests help us to form possible patterns amongst developed and developing countries as both the developed nations, the USA and Canada, have no correlation between GDP growth and respective indices growth rate. Whereas both the developing nations, China and India, have a strong or medium positive correlation. However, after testing the results for South Africa it was clear that India and China have a stronger Pearson's coefficient value not because they were developing but because India is a hub for investments currently and China is where all the multinational companies (MNCs) have their plantation unit as MNCs benefit from cheaper human capital, which in turns results in cheaper production costs.

\section{Discussion/Analysis}

The results were astonishing for the Pearson product-moment correlation coefficient. Looking at product Pearson correlation only India and China had a strong positive correlation which was "0.623" and "0.509" respectively whereas the other countries USA and Canada had an almost negligible and very weak correlation. In between those countries, South Africa comes out to be which has a value of "0.284". However, there is no theory to prove the weak correlation, which clearly shows that in the case of India and China both the GDP growth and stock market index growth goes in the same directions to some extent whereas for the USA, and Canada where the Pearson product correlation coefficient came very weak correlation which implies that GDP growth and stock index growth does not affect each other in the case of developed countries and developing countries which was made clear by the test on South Africa as the coefficient value is just "0.284". Then the results which we received from comparing GDP growth and from stock market index growth theoretically and practically were mostly easy to conceptualize which clearly shows there are no strings attached to any of the variables we compared due to consumer sentiments and how consumer confidence along with globalization and central bank activities affecting both the factors indirectly which again contradicts the point we made above that there is no comparison between the two factors. Finally, this research concludes that there might be a chance of a link between them as mentioned by Warren Buffett by an indicator he created which is Buffett Indicator, which involves market capitalization and GDP which gives buy and sell signals with a great success rate. Even though, while comparing the two factors in the practical world there is no justifiable claim which links GDP growth and stock market index growth.

Therefore, our results satisfy various past researches done on this topic by wise-owl as well as by Sachin Trivedi from UTIMF both conclude that there is no relationship between economic growth or GDP growth with stock market index growth. Then, to some extent, we even satisfy the results from Monika Halan from livemint that there is a rough estimate between the rate of growth of GDP and market return which states that GDP growth rate gives direction to stock market index growth then she further explains by mentioning the formula by warren buffet that roughly Stock market growth could be calculated by adding GDP growth, inflation, and dividend yield.

Thus, the results which we achieved from this extensive study of GDP growth and stock market index growth matches older tests done by various individuals and investment firms which were able to match GDP growth and stock market index growth theoretically but were unable to decide and conclude any theory which could link the practical results for the topic at hand.

\section{Limitations and implications}

The major limitations of this study were to not include GNP which is the gross national product to make things easier to analyze. After this, we didn't even include consumer sentiments or used any indicators in our study during the years 2000 to 2019. Moreover, we only looked upon the major indices present in the respective country. For any future research, the paper would try to even include GNP as well as include other indices and countries. 


\section{Conclusion}

This paper aimed to correlate GDP growth and stock market index growth in which we are successful as to which we used to judge the strength between GDP growth and stock market index growth. The results we achieved were imaginable to some extent which shows that there is no relation in the case of developed countries, we even discussed some of the factors which could lead us to inappropriate returns or the limitations of the project. After this, we discussed how sentiments and consumer confidence affects both equally which could lead to bullish or bearish markets through spending, saving, and borrowing.

At last, we used the famous statistics concept Pearson product-moment coefficient correlation to measure the linear correlation between two variables $\mathrm{X}$ and $\mathrm{Y}$. For various investors and also for a household who invests in the stock exchange this study could be a boon as this will assure them that the stock index won't necessarily follow GDP growth but then it might affect it so the research will help them to make better future planning.

\section{Acknowledgments}

I would like to thank all of those involved that made it possible to conduct this study and write this report. This includes my advisor, Miss Shiromi, who helped me to write and structure the research paper, Sudhi Mathur to help me realize the importance of getting the work published. Along with them, I would like to thank Karan Gurbani to go over my research at every point of the development to help me achieve unbiased results.

\section{References}

Advisorperspectives.com. (n.d.). Retrieved May 06, 2021, from https://www.advisorperspectives.com/dshort/updates/2021/05/05/market-cap-to-gdp-an-updated-look-at-the-buffettvaluation-indicator

Bernstein, W. J., \& Arnott, R. D. (2003). Earnings growth: The two percent dilution. Financial Analysts Journal, 59(5), 47-55. doi:10.2469/faj.v59.n5.2563

Buffett indicator: Where are we with Market Valuations? (n.d.). Retrieved May 06, 2021, from https://www.gurufocus.com/stock-market-valuations.php

Extrapolating growth. (2019, November 24). Retrieved May 06, 2021, from https://www.hussmanfunds.com/comment/mc180725/

Finance \& development. (n.d.). Retrieved May 06, 2021, from https://www.imf.org/external/pubs/ft/fandd/basics/gdp.htm

Gdp and its relationship with broader markets. (n.d.). Retrieved May 06, 2021, from https://www.utimf.com/articles/gdp-and-its-relationship-with-broader-markets

Government of Canada, S. (2021, May 05). Statistics Canada: Canada's national statistical agency. Retrieved May 06, 2021, from https://www.statcan.gc.ca/eng/start 
Halan, E. (2011, February 15). The link between gdp growth and the broad market index. Retrieved May 06, 2021, from https://www.livemint.com/Opinion/uWbDau6oQY50ziaJq0KqIP/The-link-between-GDP-growth-and-thebroad-market-index.html

Hall, M. (2020, September 16). How the stock market affects gdp. Retrieved May 06, 2021, from https://www.investopedia.com/ask/answers/033015/how-does-stock-market-affect-gross-domestic-product-gdp.asp

Is there a correlation between gdp growth and stock market returns? (2021, February 02). Retrieved May 06, 2021, from https://wise-owl.com/is-there-a-correlation-between-gdp-growth-and-stock-market-returns/

Is There a Link Between GDP Growth and Equity Returns? [Advertisement]. (2010, May). Retrieved May 7, 2021, from https://www.msci.com/documents/10199/a134c5d5-dca0-420d-875d-06adb948f578

Jetley, G., Watson, C., \& Breno, N. (2014). Revisiting the SUPPLY-SIDE equity risk premium [Abstract]. SSRN Electronic Journal. doi:10.2139/ssrn.2405105

Mee, K. (2017, September). GDP and earnings growth in emerging markets - a loose connection [PDF]. Schroders. Pettinger, T., Demis, Gwc, Verma, R., G., Pascal, ... Pathak, R. (2020, March 09). How does the stock market affect the economy? Retrieved May 06, 2021, from https://www.economicshelp.org/blog/221/stock-market/howdoes-the-stock-market-effect-the-economy-2/

Published by Statista Research Department, \& 22, M. (2021, March 22). U.S. GDP 1990-2019. Retrieved May 06, 2021, from https://www.statista.com/statistics/188105/annual-gdp-of-the-united-states-since-1990/

Shao, Y., Zhang, C., Zhou, J., Gu, T., \& Yuan, Y. (2019). How does Culture Shape CREATIVITY? A mini-review. Frontiers in Psychology, 10. doi:10.3389/fpsyg.2019.01219

Stock prices are a better tool to predict gdp trends, not vice-versa'. (2017, October 17). Retrieved May 06, 2021, from https://economictimes.indiatimes.com/markets/stocks/news/stock-prices-are-a-better-tool-to-predict-gdptrends-not-vice-versa/articleshow/71624242.cms

The link between gdp growth and the real estate market. (n.d.). Retrieved May 06, 2021, from https://www.asiagreen.com/en/news-insights/the-link-between-gdp-growth-and-the-real-estate-market

Three delusions: Paper wealth, a booming economy, and Bitcoin. (2019, November 24). Retrieved May 06, 2021, from https://www.hussmanfunds.com/comment/mmc171218/ 